\title{
Lymphocytes from Chronically Stressed Mice Confer Antidepressant-Like Effects to Naive Mice
}

\author{
Rebecca A. Brachman, ${ }^{1 \star} \oplus$ Michael L. Lehmann, ${ }^{1 \star}$ Dragan Maric, ${ }^{2}$ and $₫$ Miles Herkenham ${ }^{1}$ \\ ${ }^{1}$ Section on Functional Neuroanatomy, Laboratory of Cellular and Molecular Regulation, and ${ }^{2}$ NINDS Flow Cytometry Core Facility, NIH-DHHS, Bethesda, \\ Maryland 20892
}

We examined whether cells of the adaptive immune system retain the memory of psychosocial stress and thereby alter mood states and CNS function in the host. Lymphocytes from mice undergoing chronic social defeat stress or from unstressed control mice were isolated and adoptively transferred into naive lymphopenic $\mathrm{Rag} 2^{-1-}$ mice. Changes in affective behavior, hippocampal cell proliferation, microglial activation states, and blood cytokine levels were examined in reconstituted stress-naive mice. The mice receiving lymphocytes from defeated donors showed less anxiety, more social behavior, and increased hippocampal cell proliferation compared with those receiving no cells or cells from unstressed donors. Mice receiving stressed immune cells had reduced pro-inflammatory cytokine levels in the blood relative to the other groups, an effect opposite to the elevated donor pro-inflammatory cytokine profile. Furthermore, mice receiving stressed immune cells had microglia skewed toward an anti-inflammatory, neuroprotective M2-like phenotype, an effect opposite the stressed donors' M1-like pro-inflammatory profile. However, stress had no effect on lymphocyte surface marker profiles in both donor and recipient mice. The data suggest that chronic stress-induced changes in the adaptive immune system, contrary to conferring anxiety and depressive behavior, protect against the deleterious effects of stress. Improvement in affective behavior is potentially mediated by reduced peripheral pro-inflammatory cytokine load, protective microglial activity, and increased hippocampal cell proliferation. The data identify the peripheral adaptive immune system as putatively involved in the mechanisms underlying stress resilience and a potential basis for developing novel rapid-acting antidepressant therapies.

Key words: adaptive immune system; cytokines; depression; hippocampal neurogenesis; lymphocytes; stress

\section{Introduction}

Mood and cognition are generally thought of as being controlled almost exclusively by the CNS. However, peripheral systems, i.e., the endocrine and immune systems, influence behavior. Furthermore, there is a reciprocal association between the CNS and the periphery. Psychological stress and stress hormones alter the status of the immune system (Glaser and Kiecolt-Glaser, 2005), and in turn, immune system perturbations affect CNS function and structure via humoral and cellular pathways conveying signals to the brain (Maier and Watkins, 1998). The bidirectional neuroimmune pathways serve to achieve internal homeostasis (Ziemssen and Kern, 2007). Disequilibrium, if sustained or severe, results in disease (Gibney and Drexhage, 2013; Zunszain et al., 2013).

\footnotetext{
Received May 27, 2014; revised Nov. 26, 2014; accepted Dec. 3, 2014.

Author contributions: R.A.B. and M.L.L. designed research; R.A.B. and M.L.L. performed research; D.M. contributed unpublished reagents/analytic tools; M.L.L. and D.M. analyzed data; M.H. wrote the paper.

The work was supported by the National Institute of Mental Health (NIMH) Intramural Research Program, Z01 MH001090. We thank Heather Kalish, National Institute of Biomedical Imaging and Bioengineering, and Samuel Listwak; Rachel Scheinert; Mitra Haeri; and Monica Mehta, Section on Functional Neuroanatomy, NIMH, for performing assays. M.H. acknowledges his long association with the late Candace B. Pert and their discussions of the communication network between brain and body.

The authors declare no competing financial interests.

*R.A.B. and M.L.L. contributed equally to this work.

Correspondence should be addressed to Dr. Miles Herkenham, Section on Functional Neuroanatomy, LCMR, NIMH, Building 35, Room 1C913, Bethesda, MD 20892. E-mail: herkenh@mail.nih.gov.

DOI:10.1523/JNEUROSCI.2278-14.2015

Copyright $\odot 2015$ the authors $\quad 0270-6474 / 15 / 351530-09 \$ 15.00 / 0$
}

The immune system is divided into an innate arm mediating rapid general immunity and an adaptive arm mediating delayed acquired cellular immunity. Scant attention has been paid to the role played by the adaptive component in responding to and affecting mood states. It is known that chronic psychological stress affects lymphocyte numbers and function via sympathetic and steroid hormone effector pathways (Silberman et al., 2004). However, very little is known about reciprocal effects, i.e., whether stress-modulated lymphocytes in turn influence affective behavior and CNS function. Evidence exists that lymphocyte subsets adoptively transferred into or selectively deleted from mice can exert effects on cognition (Ziv et al., 2006; Brynskikh et al., 2008), mood (Cohen et al., 2006; Kim et al., 2012; Beurel et al., 2013; Rattazzi et al., 2013), and adult hippocampal neurogenesis (Wolf et al., 2009). However, there is no information about whether the psychological status of the donor animals plays a role in exerting these effects on the recipient. To address that question, we designed a simple experiment in which lymphocytes from chronically defeat-stressed or nonstressed mice were transferred to healthy, naive Rag $2^{-1-}$ mice, which lack mature lymphocytes (Shinkai et al., 1992). We found that Rag2 ${ }^{-1-}$ mice repopulated with cells from socially defeated (SD) mice showed reduced anxious and depressive-like behaviors and increased hippocampal cell proliferation, a correlate of antidepressant efficacy, compared with Rag2 ${ }^{-/-}$mice receiving either no cells or cells from home-cage (HC) control mice. We interpret the data to 
mean that psychological stress primes the adaptive immune system to confer stress resiliency to its host.

\section{Materials and Methods}

Animals. Donor and control mice were adult (10-13 weeks) male C57BL/6 mice (Taconic). Recipient mice were adult male Rag2 ${ }^{-1-}$ mice either on a C57BL/6 background (Taconic model RAGN12) or on a 129S6 background (Taconic model RAG2). Before differential housing, donor littermates were group housed in a $12 \mathrm{~h}$ light/dark colony room with lights off from 0900 to $2100 \mathrm{~h}$. Recipient mice were individually housed in sterile caging before and after adoptive transfer. The procedures were conducted in accordance with NIH guidelines and were approved by the NIMH Institutional Animal Care and Use Committee. The experimental time line is shown in Figure $1 A$.

$S D$. Repeated SD was used to induce alterations in behavioral affect in the donor mice. As described previously (Lehmann and Herkenham, 2011), an experimental intruder mouse was co-housed for $14 \mathrm{~d}$ in the home cage of a dominant aggressor CD-1 male mouse (The Jackson Laboratory). A perforated polycarbonate partition separated the pair. Each day, the partition was removed for $5 \mathrm{~min}$ to allow agonistic encounters between the pair. HC control mice were kept in grouphousing conditions.

Adoptive transfer. After $14 \mathrm{~d}$ of SD or HC, cervical, axillary, inguinal, and mesenteric lymph nodes of donor mice were removed, placed into cell-sorting medium, passed through a $70 \mu \mathrm{m}$ filter, centrifuged, resuspended in sterile physiological PBS, and injected retro-orbitally at a concentration of 10-20 million cells per host in a volume of $0.15 \mathrm{ml}$. Six days later, the injection was repeated in each host mouse with cells pooled from another set of donor mice. Recipient Rag2 $2^{-1-}$ mice received cells from either $\mathrm{SD}(\mathrm{SD} \rightarrow$ Rag $)$ or $\mathrm{HC}(\mathrm{HC} \rightarrow$ Rag $)$ mice or saline $(\mathrm{Sal} \rightarrow \mathrm{Rag})$ and were behaviorally phenotyped starting at $4 \mathrm{~d}$ after the last injection (Fig. 1A).

Flow cytometry. In a different set of animals treated as above, lymph node cells from SD or HC donor mice were harvested and prepared as above and labeled with CD3-PerCP-Cy5.5, CD4-Alexa-Fluor 647, CD8PE-Cy7, CD25-PE, and CD19-FITC (all from BioLegend). Flow cytometry was done on a MoFlo Astrios (Beckman Coulter), and data were analyzed with FlowJo software (TreeStar). For analysis of cell proliferation, donor cell suspensions from another set of mice treated as above were incubated in $5 \mu \mathrm{M}$ carboxyfluorescein diacetate succinimidyl ester (CFSE; CellTrace; Life Technologies) following manufacturer's instructions (incubated for $20 \mathrm{~min}$ at room temperature and washed) and injected into Rag $2^{-/-}$hosts (5-10 million cells per animal on days 1 and 6, followed by harvest on day 14). Recovered cells were labeled with CD3PerCP-Cy5.5 and B220-Alexa Fluor 647 (BioLegend).

Behavioral analysis. Beginning $10 \mathrm{~d}$ after the first transfer, the host Rag2 ${ }^{-1-}$ mice were tested in one behavioral test per day. Group-housed control C57BL/6 mice (WT) were run as well. Automated video-based tracking of behavior was done as previously described (TopScan and TailSuspScan; Cleversys; Lehmann et al., 2013b, 2013c).

Light/dark (L/D) box. The light/dark box test was conducted in a $50 \times$ $25 \times 30 \mathrm{~cm}$ Plexiglas box divided into dark (one-third of total area) and light compartments separated by an open door. Time spent in the light compartment and transitions between compartments during $10 \mathrm{~min}$ were measured.

Open-field test $(O F T)$. Mice were placed into a $50 \times 50 \times 50 \mathrm{~cm}$ openfield arena for $30 \mathrm{~min}$. Time spent in the center of the open field (middle $50 \%$ of the arena) was measured as an indicator of anxiety-like behavior.

Social interaction (SI). Mice were placed in the open-field arena containing two upside-down wire cages. One cage contained an aggressor CD-1 mouse used during SD. Test mice were placed in the open field and allowed to explore for $30 \mathrm{~min}$. Their locations were recorded from above. Social interaction quotients following the interaction task were quantified as a ratio between duration investigating the aggressor CD-1 mouse and the empty cup.

Urine scent-marking (USM). A spot of urine from an estrous female mouse was placed in one corner of blotting paper covering the open-field floor. Test mice were placed in the arena and allowed to freely explore and scent mark for $10 \mathrm{~min}$. The urine tracks were revealed by ninhydrin staining, the sheets photographed and digitally binarized, and the marked areas quantified (ImageJ). Dividing the area of marks in a circle within $10 \mathrm{~cm}$ of the female urine spot by the total area of marks in the arena provided the marking preference.

Tail-suspension test (TST). The mouse was suspended by its tail $60 \mathrm{~cm}$ above the floor for $6 \mathrm{~min}$, and the time spent immobile and mobile was recorded.

Hippocampal cell proliferation analysis by BrdU immunohistochemistry. One day after behavioral testing, BrdU (Sigma-Aldrich) was administered intraperitoneally at $200 \mathrm{mg} / \mathrm{kg}$. Three hours later, mice were deeply anesthetized and perfused transcardially with $0.9 \%$ saline followed by phosphate-buffered 4\% PFA. Brains were coronally sectioned at $50 \mu \mathrm{m}$ throughout the rostrocaudal extent of the hippocampus. Free-floating sections were washed in PBS, subjected to citric acid antigen retrieval (15 min at $95^{\circ} \mathrm{C}$ ), washed, blocked in $4 \%$ normal goat serum, incubated overnight at $4^{\circ} \mathrm{C}$ in monoclonal rat anti-BrdU antibody (1:500; Sigma), and incubated in biotinylated anti-rat IgG (1:250), avidin-biotin-horseradish peroxidase, and DAB (all from Vector Laboratories). Stained cells in the dentate gyrus subgranular layer were counted from every 12th slide-mounted section.

Corticosterone radioimmunoassay. Mice were placed in the open field under social interaction (SI) conditions for $20 \mathrm{~min}$ to serve as a mild stressor, and then trunk blood was collected by cardiac puncture just before perfusion for the immunohistochemistry. Corticosterone in the serum was measured by radioimmunoassay (Corticosterone ${ }^{125}$ I RIA Kit; MP Biochemicals) according to the manufacturer's instructions.

Serum protein determinations. Serum was analyzed according to manufacturer's instructions by MS Q-Plex Mouse Cytokine screen (Quansys) measuring IL- $1 \alpha$, IL- $1 \beta$, IL-2, IL-3, IL-4, IL-5, IL-6, IL-10, IL-12p70, IL-17, MCP-1, IFN $\gamma$, TNF $\alpha$, MIP- $1 \alpha$, GMCSF, and RANTES.

Microglial gene expression ex vivo. Whole brains minus cerebellum were dissected from $\mathrm{HC}$ and SD donors, and from Rag2 ${ }^{-1-}$ recipient groups $\mathrm{SD} \rightarrow \mathrm{Rag}, \mathrm{HC} \rightarrow \mathrm{Rag}$, and $\mathrm{Sal} \rightarrow$ Rag. Single-cell suspensions were created through enzymatic digestion using the Neural Tissue Dissociation Kit (Miltenyi Biotec) for $35 \mathrm{~min}$ at $37^{\circ} \mathrm{C}$. Further processing was performed at $4^{\circ} \mathrm{C}$. Tissue debris was removed by passing the cell suspension through a $40 \mu \mathrm{m}$ cell strainer. Myelin was removed using a discontinuous Percoll gradient. After enzymatic dissociation, cells were resuspended in 70\% Percoll layered under 30\% Percoll and banded on a $70 \%$ Percoll cushion at $1000 \times g$ at $10^{\circ} \mathrm{C}$ for $40 \mathrm{~min}$. The supernatant containing myelin was removed, and cells at the $30-70 \%$ Percoll interface were labeled with magnetic CD11b micro beads (Miltenyi). Using the manufacturer's guidelines, $\mathrm{CD} 11 \mathrm{~b}+$ cells were separated in a magnetic field using MS columns (Miltenyi). Isolated CD11b + cells were stained with trypan blue, and the number of live and dead cells was counted under the microscope based on dye exclusion. Each brain extraction yielded $\sim 3 \times 10^{5}$ viable cells. Cells were suspended in DMEM F12 + GlutaMAX supplemented with $10 \%$ qualified FBS and plated at $1 \times 10^{5}$ cells/well on poly-D-lysine-coated 12 -well plates. Cells were incubated at $37^{\circ} \mathrm{C}$ for $1 \mathrm{~h}$, then stimulated either with media, LPS (serotype 055:B5; Sigma; $150 \mathrm{ng} / \mathrm{ml}$ ), or recombinant mouse IL-4 (20 ng/ml; $\mathrm{R} \& \mathrm{D}$ Systems) at $37^{\circ} \mathrm{C}$ for $3 \mathrm{~h}$. Cells from each brain were exposed to all three conditions. The stimulation assays were used to detect microglial polarization known for macrophages as classically activated (M1) or alternatively activated (M2), respectively (Kigerl et al., 2009). After $3 \mathrm{~h}$ of stimulation, the cells were pelleted, and $500 \mu \mathrm{l}$ TRIzol (Life Technologies) was added. Total RNA was extracted using a commercial kit (Qiagen) and reverse transcribed using a Superscript III First Strand cDNA Synthesis Kit (Invitrogen). Two-step real-time RT-PCR with $2 \times$ SYBR Green Master Mix (Bio-Rad) was performed using the Bio-Rad iCycler. The genes examined were traditional M1-like, IL-1 $\beta$ and IL-6, and M2-like, mannose receptor, $\mathrm{C}$ type 1 (MRC1) and arginase (ARG1). The endogenous GAPDH gene was used to normalize quantification of the mRNA target. Relative expression levels were determined by the $\Delta \Delta \mathrm{Ct}$ method, and the data were expressed as the fold change relative to the HC media-stimulated sample. Gene expression was considered undetectable if the $\mathrm{Ct}$ value was $>35$ cycles.

RT-PCR was performed using the following primers: GAPDH; Forward5' -CAAAATGGTGAAGGTCGGTGTGReverse 5'-TGATGTTAGT 

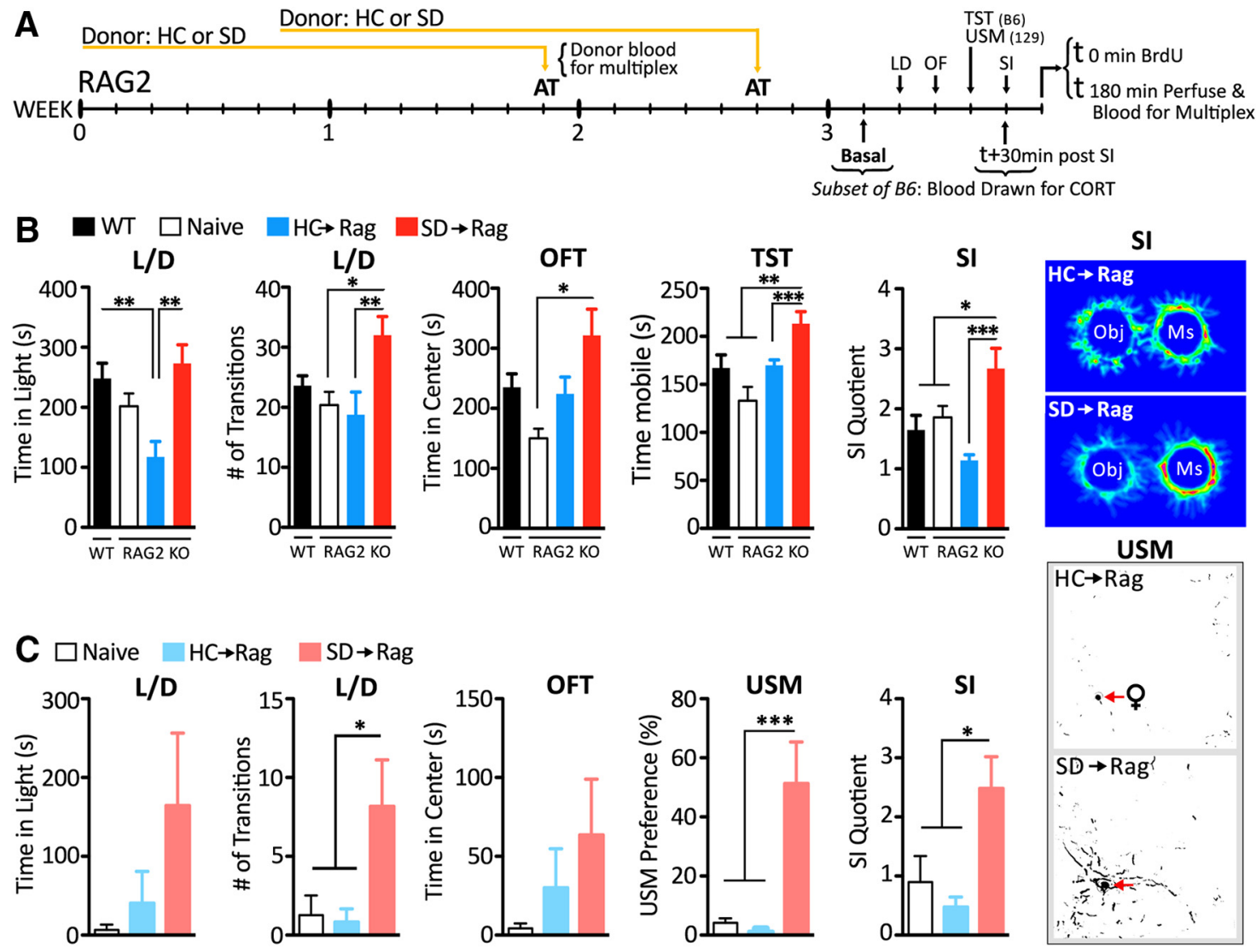

Figure 1. Transfer of lymphocytes from stressed mice confers behavioral resilience in two strains of Rag ${ }^{-1-}$ mice. The experimental time line is shown in $A$. Following adoptive transfer (AT) of cells from SD or HC donors, SD $\rightarrow$ Rag mice on a C57BL/6 background ( $n=12-16$ per group; $\boldsymbol{B})$ showed increased time in light and elevated transitions in the L/D box, increased center time in the OFT, increased mobility in the TST, and enhanced preference for SI. Behavioral profiles between C57BL/6 WT and naive Rag $2^{-1-}$ mice on the same background were comparable. SD $\rightarrow$ Rag mice on 129 background ( $n=6-8$ per group; $($ ) showed comparable anxiolytic changes in the L/D test and significantly enhanced expressions of socially affiliative behaviors measured in the USM and SI tests. Post hoc significances marked. ${ }^{*} p<0.5 ;{ }^{* *} p<0.01 ;{ }^{* * *} p<0.001$. Heat maps show digitized behavior in the SI task, and binarized maps show marking behavior to female urine in the USM test.

GGGGTCTCGCTC, IL-1 $\beta$; Forward 5'-TGTCTTTCCCGTGGACCT TC Reverse 5'-CTAATGGGAACGTCACACACC, IL-6; Forward 5'TCTGGGAAATCGTGGAAATGAGReverse 5' -TCTCTGAAGGACTCT GGCTTTGTC, MRC1; Forward 5'-TCTTTGCCTTTCCCAGTCTCC Reverse 5' -TGACACCCAGCGGAATTTC, ARG; Forward 5' -AGCCAA TGAAGAGCTGGCTGGT, Reverse 5' -AACTGCCAGACTGTGGTCTCCA.

\section{Statistics}

One-way ANOVA followed by Bonferroni post-test or Student's $t$ test was conducted using SPSS software. Data are presented as mean \pm SEM.

\section{Results}

\section{Effect of adoptive transfer on affective behavior}

Previous work has shown that $10 \mathrm{~d}$ to 2 weeks after adoptive transfer to lymphopenic mice, lymphocytes have migrated to the spleen and lymph nodes, proliferated, and reached a plateau (Murali-Krishna and Ahmed, 2000). At this stage, the recipient Rag2 ${ }^{-1-}$ mice were behaviorally phenotyped (Fig. $1 A$ ).

Rag2 ${ }^{-1-}$ mice on C57BL/6 background were tested in four tasks (Fig. $1 B$ ). In the L/D box test for anxiety, mice that received cells from $\mathrm{HC}$ mice $(\mathrm{HC} \rightarrow \mathrm{Rag})$ spent less time in the light than naive $\mathrm{C} 57 \mathrm{BL} / 6$ and $\mathrm{SD} \rightarrow$ Rag mice, suggesting an anxiogenic effect of HC cells $\left(F_{(3,49)}=6.80, p<0.001\right)$. When we measured the number of transitions between light and dark compartments, which is considered the more salient measure of anxiety-like behavior in the L/D test (Crawley, 1985), the SD $\rightarrow$ Rag mice made more transitions than either the naive (saline-injected) Rag2 ${ }^{-1-}$ or $\mathrm{HC} \rightarrow$ Rag mice $\left(F_{(3,49)}=4.24 p<0.01\right)$, suggesting an anxiolytic effect of SD cells. In the open-field test (OFT), activity measured by distance traveled in $30 \mathrm{~min}$ showed a main effect $\left(\mathrm{Rag}^{-/-}\right.$naive $115 \pm 3.6$, B6 WT $96 \pm 5.5, \mathrm{HC} \rightarrow \operatorname{Rag} 92 \pm 4.5$, and $\left.\mathrm{SD} \rightarrow \operatorname{Rag} 110 \pm 8.8 \mathrm{~m} ; F_{(3,49)}=3.29, p=0.03\right)$, but no post hoc significance was found, indicating that neither the gene deletion and lymphopenic state nor the addition back of donor cells had an effect on overall activity levels. Time spent in the center is an index of anxiety, and relatively increased center time displayed by the $\mathrm{SD} \rightarrow$ Rag mice relative to naive $\operatorname{Rag} 2^{-1-}$ mice $\left(F_{(3,49)}=\right.$ $4.80, p<0.005)$ is suggestive of an anxiolytic effect. In the SI test, $\mathrm{SD} \rightarrow$ Rag mice showed more interaction with the CD-1 mouse than did all of the other groups $\left(F_{(3,49)}=7.47, p<0.001\right)$, suggesting a greater sociability in these mice. In the tail-suspension test (TST), where immobility is a measure of depressive-like states, the $\mathrm{SD} \rightarrow \mathrm{Rag}$ mice showed more time mobile than the naive Rag mice $\left(F_{(3,49)}=\right.$ 8.60, $p<0.0001)$. Thus in all tests, the $\mathrm{SD} \rightarrow$ Rag group showed reductions in anxiety- and depressive-like behaviors relative to other groups.

$\operatorname{Rag} 2^{-1-}$ mice on a 129 background were subjected to behavioral tests for activity and anxiety following adoptive transfer (Fig. 1C). Mice on this background are overall less active than $\mathrm{C} 57 \mathrm{BL} / 6$ mice. In the $\mathrm{L} / \mathrm{D}$ box, naive Rag mice and $\mathrm{HC} \rightarrow \mathrm{Rag}$ mice showed less time in the light $\left(F_{(2,19)}=2.47, p=0.1, \mathrm{~ns}\right)$ and very few transitions $\left(F_{(2,19)}=4.88, p<0.05\right)$ between compart- 


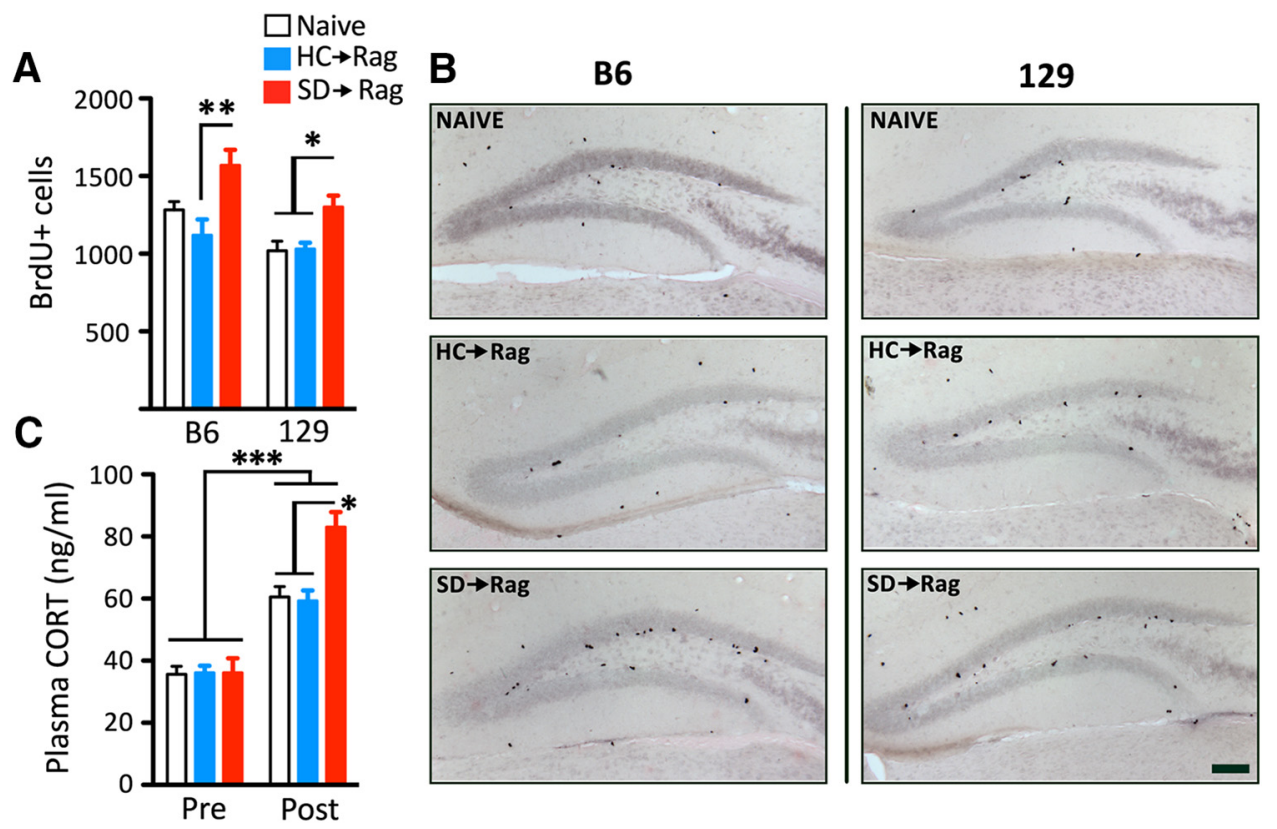

Figure 2. Transfer oflymphocytes from stressed mice increases hippocampal DG cell proliferation in the C57BL/6(A) and $129(B)$ strains of Rag2 ${ }^{-1-}$ mice and increases SI-induced corticosterone (CORT) levels in C57BL/6 mice ( $n=10-16$ per group; C). The increases in SD $\rightarrow$ Rag mice were relative to naive and $\mathrm{HC} \rightarrow$ Rag mice with significances indicated. Representative photomicrographs of the BrdU-labeled cells in the DG of the two strains are shown. Scale bar, $100 \mu \mathrm{m}$.

ments. In contrast, $\mathrm{SD} \rightarrow$ Rag mice ventured out into the light and showed significantly more transitions than the other groups $(p<$ $0.05)$. In the OFT, there was a main activity effect (Rag2 ${ }^{-l-}$ naive $21.4 \pm 3.1, \mathrm{HC} \rightarrow \operatorname{Rag} 18.6 \pm 3.3$, and $\mathrm{SD} \rightarrow \operatorname{Rag} 34.2 \pm 4.8 \mathrm{~m}$; $\left.F_{(2,19)}=4.71, p=0.02\right)$, and the SD $\rightarrow$ Rag mice traveled more than $\mathrm{HC} \rightarrow$ Rag mice $(p<0.05)$. The anxiety component was also affected. Naive 129 Rag2 ${ }^{-/-}$mice strongly avoided the center, and $\mathrm{HC} \rightarrow$ Rag and $\mathrm{SD} \rightarrow$ Rag mice spent more time in the center, with great variability in the data $\left(F_{(2,19)}=1.82, p=0.19\right)$. In the urine scent-marking (USM) and SI tests, which both measure sociability, the naive $129 \mathrm{Rag}$ and $\mathrm{HC} \rightarrow$ Rag mice showed very low scent-marking preferences and little interaction with the CD-1 mouse, whereas the $\mathrm{SD} \rightarrow$ Rag mice showed robust marking preference $\left(F_{(2,19)}=13.77, p<0.001\right)$ and SI $\left(F_{(2,19)}=6.05, p<\right.$ $0.01)$. The effect of SD cells on behavior was so profound, it appeared almost as a qualitative change-making a $129 \mathrm{Rag} 2^{-1-}$ mouse behave as if it were a C57BL/6 Rag $2^{-1-}$ mouse.

\section{Hippocampal cell proliferation and plasma corticosterone levels are differentially affected by the prior histories of the transferred cells}

Hippocampal neurogenesis is correlated with changes in affect; it is decreased by psychological stressors and increased by antidepressant interventions (Schloesser et al., 2010; Lehmann et al., 2013a). Nuclear BrdU incorporation in the hippocampal DG at $3 \mathrm{~h}$ post injection marks newborn cells, and most of those that survive are fated to become neurons. However, neuronal cell fate could not be explicitly determined because of the brief time window. Throughout the extent of the DG, there were significantly more $(\sim 50 \%)$ newborn cells in the $\mathrm{SD} \rightarrow$ Rag group than the $\mathrm{HC} \rightarrow$ Rag group on the C57BL/6 background $\left(F_{(2,40)}=6.4, p<\right.$ $0.005)$ and the $\mathrm{HC} \rightarrow \mathrm{Rag}$ and naive $\mathrm{Rag} 2^{-1-}$ groups on the 129 background $\left(F_{(2,18)}=6.1, p<0.02\right.$; Fig. $\left.2 A, B\right)$. Interestingly, in mice on the $\mathrm{C} 57 \mathrm{BL} / 6$ background, corticosterone levels in the $\mathrm{SD} \rightarrow$ Rag group were significantly higher than in the $\mathrm{HC} \rightarrow \mathrm{Rag}$ and Sal $\rightarrow \operatorname{Rag} 2^{-1-}$ groups $\left(F_{(2,39)}=11.24, p<0.001\right.$; Fig. $\left.2 C\right)$.
Cytokine profiles in the blood of donor and recipient mice show opposite stress-induced and stressed cell-induced changes

Chronic defeat stress affected the blood cytokine levels in the donor mice by increasing TNF $\alpha$, IL-1 $\beta$, IL-2, IL-3, IL-6, IL-17, and IFN $\gamma$ in the SD relative to HC groups ( $t$ test for SD vs HC: $p<$ 0.05 to $p<0.001$; Fig. 3; data not shown). Interestingly, in the $\operatorname{Rag} 2^{-/-}$recipient mice, the levels of TNF $\alpha, \mathrm{L}-1 \beta$, IL-2, IL-3, and IL-17 were reduced in $\mathrm{SD} \rightarrow$ Rag compared with $\mathrm{HC} \rightarrow$ Rag mice, and thus the direction of the difference was opposite the donor mice with respect to the stress effect (ANOVA: $F_{(2,12)}, p<0.02$ to $p<0.001)$. As a reference, naive Rag $2^{-1-}$ mice had levels that fell between the $\mathrm{HC} \rightarrow$ Rag and $\mathrm{SD} \rightarrow$ Rag levels for some cytokines (IL- $1 \alpha$, IL- $1 \beta$, IL-2, IL-4, IL-17, and TNF $\alpha$ ). Significant differences are indicated in Figure 3.

\section{Microglial M1/M2 gene expression profiles are reversed between donor and recipient mice}

We explored whether lymphocyte regulation of behavior and hippocampal cell proliferation following adoptive transfer might be achieved via peripheral humoral and cellular influences that gain entry into the brain and target microglia, which are the brain's immune cells capable of responding to signals emanating from the adaptive immune system and modifying neuronal function (Schwartz and Shechter, 2010). We examined the activation state of microglia using an ex vivo approach that has been validated in psychological stress models (Frank et al., 2007). We further determined the "classical" M1 inflammatory polarization and the "alternative" M2 anti-inflammatory/neuroprotective polarization (Cherry et al., 2014) of the microglia by measuring the gene expression levels of M1 markers, IL- $1 \beta$ and IL-6, and M2 markers, MRC1 and ARG1, in cells from both donors and Rag2 ${ }^{-1-}$ recipients. Cells were assayed in their basal state and following $3 \mathrm{~h}$ stimulation by LPS, the M1 polarizing stimulus, and by IL-4, the M2 polarizing stimulus (Table 1). Microglia from SD donor mice showed elevated basal expression of the M1 cyto- 

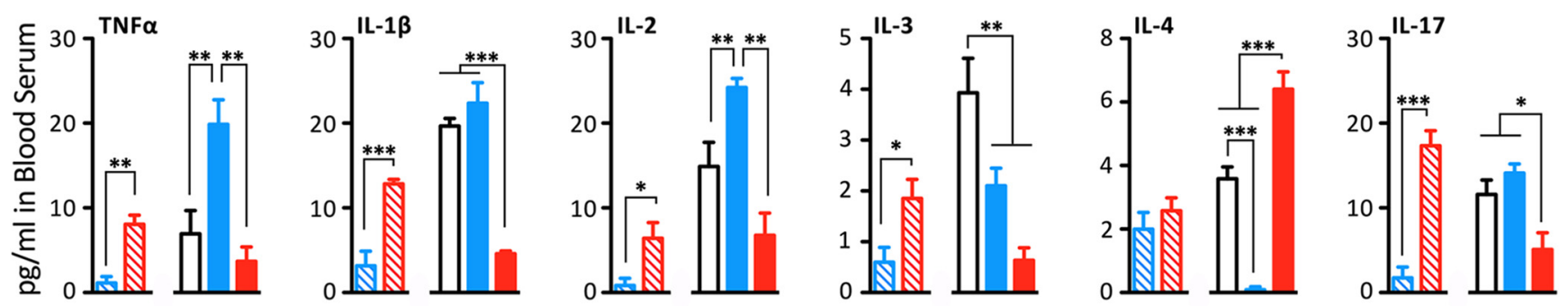

Donor: $\$ H C \otimes S D \quad$ Recipient: $\square$ Naive $\square$ HC $\rightarrow$ Rag $\square S D \rightarrow$ Rag

Figure 3. Levels of several plasma cytokines are increased by SD stress relative to $\mathrm{HC}$ control mice, but the relationship is reversed in Rag ${ }^{-/-}$mice receiving cells from those animals. In $\mathrm{HC} \rightarrow$ Rag mice elevations relative to naive control were seen for some cytokines. In the SD $\rightarrow$ Rag mice, reductions in levels were seen for pro-inflammatory cytokines and increases in levels of the anti-inflammatory cytokine IL-4 were seen relative to the other groups, with significances shown ( $n=4-6$ per group).

Table 1. Microglial M1/M2 phenotype is differentially altered by chronic stress exposure in donor mice and by the source of stressed cells in Rag2 ${ }^{-1-}$ recipient mice

\begin{tabular}{lllll}
\hline Gene: treatment & HC & SD & $H C \rightarrow$ Rag & SD $\rightarrow$ Rag \\
\hline IL-1 $\beta$ & & & & \\
Media & $1.10 \pm 0.22$ & $2.39 \pm 0.28^{*}$ & $1.39 \pm 0.46$ & $0.78 \pm 0.19$ \\
IL-4 & $1.67 \pm 0.23$ & $1.51 \pm 0.29$ & $0.88 \pm 0.17$ & $0.92 \pm 0.16$ \\
LPS & $7.15 \pm 0.96^{* * *}$ & $20.4 \pm 3.31^{* * * \#}$ & $8.95 \pm 0.80^{* * *}$ & $5.16 \pm 0.93^{* * *}$ \\
IL-6 & & & $1.50 \pm 0.06$ \\
Media & $1.06 \pm 0.16$ & $2.73 \pm 0.26^{* * *}$ & $2.02 \pm 0.27^{* *}$ & $1.33 \pm 0.16$ \\
IL-4 & $0.94 \pm 0.15$ & $1.92 \pm 0.54$ & $2.20 \pm 0.41$ & $1.64 \pm 0.19$ \\
LPS & $6.20 \pm 1.04^{* * *}$ & $13.7 \pm 1.72^{* * * \#}$ & $17.6 \pm 2.14^{* * * \#}$ & $7.82 \pm 0.91^{* * *}$ \\
MRC1 & & & $1.74 \pm 0.16^{*}$ \\
Media & $1.03 \pm 0.15$ & $0.6 \pm 0.08$ & $0.54 \pm 0.09^{* * *}$ & $1.71 \pm 0.17$ \\
IL-4 & $1.74 \pm 0.39$ & $1.61 \pm 0.44$ & $0.76 \pm 0.12$ & $1.14 \pm 0.15$ \\
LPS & $0.83 \pm 0.18$ & $0.67 \pm 0.12$ & $0.36 \pm 0.08^{* * * \#}$ & $0.62 \pm 0.13$ \\
ARG1 & & & \\
Media & $1.04 \pm 0.14$ & $0.87 \pm 0.25$ & $0.56 \pm 0.05$ & $0.65 \pm 0.05$ \\
IL-4 & $22.0 \pm 2.51^{* * *}$ & $9.13 \pm 1.63^{* * * \#}$ & $2.98 \pm 0.44^{* * * \#}$ & $0.73 \pm 014$ \\
LPS & $1.33 \pm 0.33$ & $1.12 \pm 0.17$ & $1.12 \pm 0.27$ & $4.81 \pm 0.72^{* * * \#}$ \\
\hline
\end{tabular}

Values represent mean fold change \pm SEM in gene expression compared to HC Media-stimulated samples $(n=6)$. Means with asterisk indicate significant difference versus $\mathrm{HC}$ media $\left({ }^{*} p<0.05\right.$, $\left.{ }^{* *} p<0.01,{ }^{* * *} p<0.005\right)$. $\#$ indicates significance versus within-treatment $\mathrm{HC}$ sample $(p<0.01)$.

kines IL- $1 \beta$ and IL- 6 . They also showed reduced basal expression of the M2 marker MRC1 and muted ARG response to IL-4. As expected, the response of the M1 cytokines to LPS was massive in all treatment conditions, but it was greater in SD than HC cells.

The M1 polarizing effect of SD in donor microglia was reversed in recipient $\mathrm{SD} \rightarrow$ Rag microglia, i.e., lymphocytes from stressed donors skewed microglia in the Rag $2^{-1-}$ hosts toward an M2-like phenotype (Table 1). Microglia from SD $\rightarrow$ Rag mice showed a robust elevation in ARG expression (basal and IL-4 stimulated) and a generally muted response of IL-1 $\beta$ and IL-6 to LPS stimulation relative to microglia from $\mathrm{HC} \rightarrow \mathrm{Rag}$ and $\mathrm{Sal} \rightarrow \mathrm{Rag}$ mice. In comparison, cells from $\mathrm{HC} \rightarrow \mathrm{Rag}$ mice had a significant increase in IL-6 (basal and LPS-stimulated) but significant reductions in basal MRC1 and ARG expression compared with basal levels of $\mathrm{HC}$ donor cells. $\mathrm{HC} \rightarrow \mathrm{Rag}$ cells also showed diminished response of MRC1 to LPS compared with LPStreated HC cells and a diminished ARG response to IL-4 compared with IL-4-stimulated HC cells. These patterns were typically found also in the cells from $\mathrm{Sal} \rightarrow$ Rag mice that received no adoptive transfer, suggesting that cell transfer of lymphocytes from $\mathrm{HC}$ mice contributed little or nothing to the microglial environment in lymphopenic mice.

Lymphocyte subpopulations in the donor and recipient mice are not differentially affected by defeat stress

Cells taken from lymph nodes, spleen, and blood of SD and HC donor mice and recipient $\mathrm{HC} \rightarrow \mathrm{Rag}$ and $\mathrm{SD} \rightarrow$ Rag mice were marked with CD19 (B cells), CD3 (T cells), CD4 (T helper), CD8 ( $\mathrm{T}$ cytotoxic), and $\mathrm{CD} 25$ ( $\mathrm{T}$ regulatory) antibodies for cellsorting analysis. Donor SD and HC mice showed no differences in relative cell numbers in lymph nodes (Fig. 4), spleen, blood, or in individual lymph node pools isolated from cervical, axillary, inguinal, and mesenteric sources for the markers used (data not shown). Saline-injected Rag $2^{-1-}$ mice had virtually no T cells or B cells in their lymph nodes, as expected (Fig. 4). The profile of cells in $\mathrm{SD} \rightarrow \mathrm{Rag}$ and $\mathrm{HC} \rightarrow \mathrm{Rag}$ lymph nodes, spleen, and blood indicated that $\mathrm{T}$ cells remained abundant in both groups, but B cells dropped from $\sim 14 \%$ of the viable cells in the donor lymph nodes to $\sim 6 \%$ in the Rag $2^{-1-}$ host lymph nodes (Fig. 4), and they represented $2 \%$ in the spleen and $<1 \%$ in the blood (Table 2). The relative numbers of $\mathrm{CD}^{+}$and $\mathrm{CD}^{+}$cells were similar between $\mathrm{HC}$ and SD donors, and the proportions did not change in the $\mathrm{HC} \rightarrow \mathrm{Rag}$ and $\mathrm{SD} \rightarrow \mathrm{Rag}$ recipients. The $\mathrm{CD} 4{ }^{+} / \mathrm{CD} 8{ }^{+}$cell ratios in the host mice were different in different tissues (CD8 $>$ CD4 in lymph nodes and spleen, but CD4 $>$ CD8 in blood), but they were not different in the stress versus unstressed conditions. Treg cells remained fairly constant in relative number in donors and hosts (Fig. 4, Table 2).

\section{Lymphocyte proliferation is the same in $\mathrm{HC} \rightarrow \mathrm{Rag}$ and $\mathrm{SD} \rightarrow$ Rag mice}

Cell proliferation was determined by flow cytometry of CFSE prelabeled lymph node cells transferred to Rag $2^{-1-}$ mice on days 1 and 6 and assayed on day 14. CFSE binds irreversibly and ubiq- 

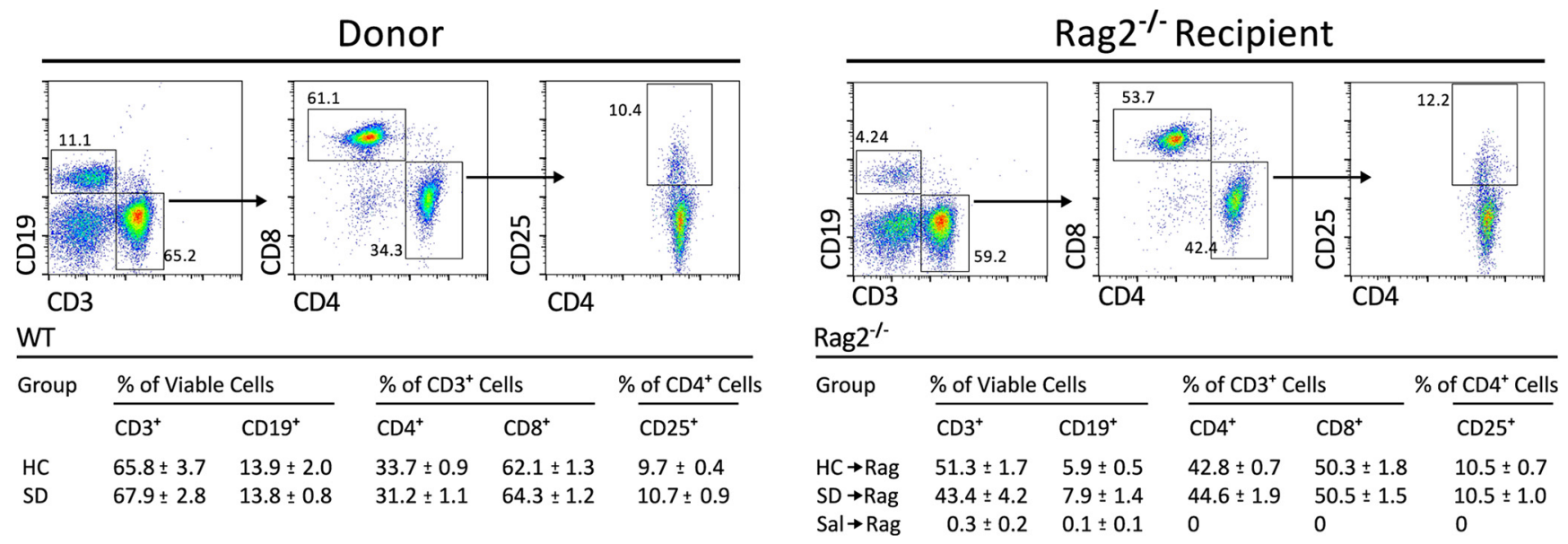

Figure 4. The relative abundance of lymphocyte subpopulations was not affected by SD stress compared with HC control conditions ( $n=6$ per group). Representative bivariate dot plots show lymphocytes from donor mice and host Rag2 ${ }^{-1-}$ mice (examples are from lymph nodes taken from mice in defeat conditions) stained and gated for $B$ cells, T cells, and $T$ cell subsets. The table shows that ratios of $\mathrm{CD} 19^{+}, \mathrm{CD} 3^{+}, \mathrm{CD} 4^{+}$, and $\mathrm{CD} 8{ }^{+}$cells as well as the proportion of $\mathrm{CD2} 25^{+}$regulatory $\mathrm{CD} 4^{+} \mathrm{T}$ cells were not affected.

Table 2. Enumeration of lymphocyte subsets in spleen and blood of host Rag2 $2^{-/-}$ mice

\begin{tabular}{|c|c|c|c|c|c|}
\hline \multirow[b]{2}{*}{ Group } & \multicolumn{2}{|c|}{$\%$ of viable cells } & \multicolumn{2}{|c|}{$\%$ of $\mathrm{CD}^{+}{ }^{+}$cells } & \multirow{2}{*}{$\frac{\% \text { of } \mathrm{CD}^{+}{ }^{+} \text {cells }}{\mathrm{CD} 25^{+}}$} \\
\hline & $\mathrm{CD}^{+}$ & $\mathrm{CD}_{1} 9^{+}$ & $\mathrm{CD}^{+}$ & $\mathrm{CD}^{+}$ & \\
\hline \multicolumn{6}{|l|}{ Spleen } \\
\hline $\mathrm{HC} \rightarrow \mathrm{Rag}$ & $11.1 \pm 0.9$ & $2.3 \pm 0.3$ & $36.3 \pm 0.8$ & $58.2 \pm 1.4$ & $6.1 \pm 1.3$ \\
\hline$S D \rightarrow$ Rag & $11.4 \pm 1.7$ & $1.9 \pm 0.4$ & $36.9 \pm 2.6$ & $59.0 \pm 2.5$ & $7.3 \pm 0.9$ \\
\hline $\mathrm{Sal} \rightarrow \mathrm{Rag}^{a}$ & $0.3 \pm 0.1$ & $0.1 \pm 0.1$ & 0 & 0 & 0 \\
\hline \multicolumn{6}{|l|}{ Blood } \\
\hline $\mathrm{HC} \rightarrow \mathrm{Rag}$ & $18.6 \pm 4.7$ & $0.1 \pm 0.0$ & $46.1 \pm 5.7$ & $42.0 \pm 8.6$ & $0.7 \pm 0.4$ \\
\hline $\mathrm{SD} \rightarrow$ Rag & $21.4 \pm 2.9$ & $0.3 \pm 0.1$ & $47.1 \pm 5.4$ & $42.8 \pm 5.3$ & $0.9 \pm 0.1$ \\
\hline $\mathrm{Sal} \rightarrow \mathrm{Rag}^{a}$ & $0.3 \pm 0.3$ & $0.1 \pm 0.1$ & 0 & 0 & 0 \\
\hline
\end{tabular}

uitously to cell proteins, and its fluorescent intensity level drops by half with each cell division, which can be seen as individual peaks in the intensity histogram. Before transfer, all lymph node cells had a single peak of high intensity (Fig. 5). Proliferation of lymphocytes in a lymphopenic host such as the Rag $2^{-1-}$ mouse is referred to as homeostatic or spontaneous proliferation (Min et al., 2004), and it occurs extensively (Ernst et al., 1999). This phenomenon was documented in our mice. After transfer into $\operatorname{Rag} 2^{-1-}$ mice, few undivided cells remained, and most cells had undergone more than eight divisions in both lymph nodes and spleen. There were no significant differences in the proliferation rates between $\mathrm{HC} \rightarrow$ Rag and $\mathrm{SD} \rightarrow$ Rag mice. Representative histograms for CD3-gated T cells from lymph nodes are shown in Figure 5. Similar proliferation patterns were found for lymph node B cells and for T cells and B cells harvested from the spleens (data not shown).

\section{Discussion}

There is growing evidence that mood states are influenced by communication between the immune system and the brain. Mood disorders are associated with immune activation characterized mainly by elevated levels of pro-inflammatory cytokines and altered levels and trafficking of leukocytes (Dantzer et al., 2008; Miller et al., 2009). The general current view holds that this neuro-immune cross talk creates a downward spiral of increasing pathophysiology in both the immune system and the brain. But this viewpoint overlooks the immune system's proactive agenda-to achieve homeostasis in conditions of disequilibrium. The data pre- sented here show that lymphocytes of the adaptive immune system are programmed by psychosocial stress in a way that allows them to confer anti-stress effects on the host when given the opportunity. Cells from SD but not $\mathrm{HC}$ mice conferred an anxiolytic and antidepressant phenotype onto lymphopenic $\mathrm{Rag} 2^{-1-}$ mice. The effect was so dramatic in the 129 strain of Rag $2^{-1-}$ mice that the behavioral phenotype was actually qualitatively altered-mice that normally display few measurable behaviors on their own demonstrated levels of activity and social interaction after $\mathrm{SD} \rightarrow$ Rag transfers that were more typical of C57BL/6 mice.

In both strains of Rag $2^{-1-}$ mice, transfer of cells from defeated mice increased new cell proliferation in the dentate gyrus relative to the other groups. Interestingly, the transfer from defeated mice also elevated corticosterone levels in the SD $\rightarrow$ Rag group relative to the others. These parallel elevations are reminiscent of our finding that environmental enrichment, which confers stress resilience (Lehmann and Herkenham, 2011), elevates corticosterone levels and promotes neurogenesis in mouse hippocampus (Lehmann et al., 2013a). Thus, contrary to the usual association of elevated corticosterone with decreased neurogenesis in "distress" conditions (Gould and Tanapat, 1999), the present data suggest that a "eustress" effect had been conferred onto the host mice by lymphocytes from stressed mice.

We also examined the effects of defeat stress on lymphocyte phenotype before transfer. Relative ratios of B cells, T cells, and $\mathrm{T}$ cell subsets in donor lymph nodes, spleen, and blood were not grossly altered by SD compared with $\mathrm{HC}$, suggesting that other markers of cell type and activation state are needed to show differences. We did not measure absolute numbers of lymphocytes or their ex vivo response to immune challenge, which might have revealed differences (Frick et al., 2009). Human studies have shown varied effects of psychological stress on lymphocyte subpopulations and function (Zorrilla et al., 2001; Segerstrom and Miller, 2004). Similar examination of the fate of transferred lymphocytes revealed that $\mathrm{T}$ cells predominated in lymph nodes, spleens, and blood, and there were no differences in relative numbers of T-cell subsets between groups.

Previous work using the adoptive transfer model emphasized the roles of specific lymphocyte subsets that affect mood states and cognition, i.e., autoreactive (Cohen et al., 2006; Ziv et al., 2006), regulatory (Treg; Kim et al., 2012), helper (Th; Rattazzi et al., 2013), and Th17 (Beurel et al., 2013) T cells. Summarizing the 

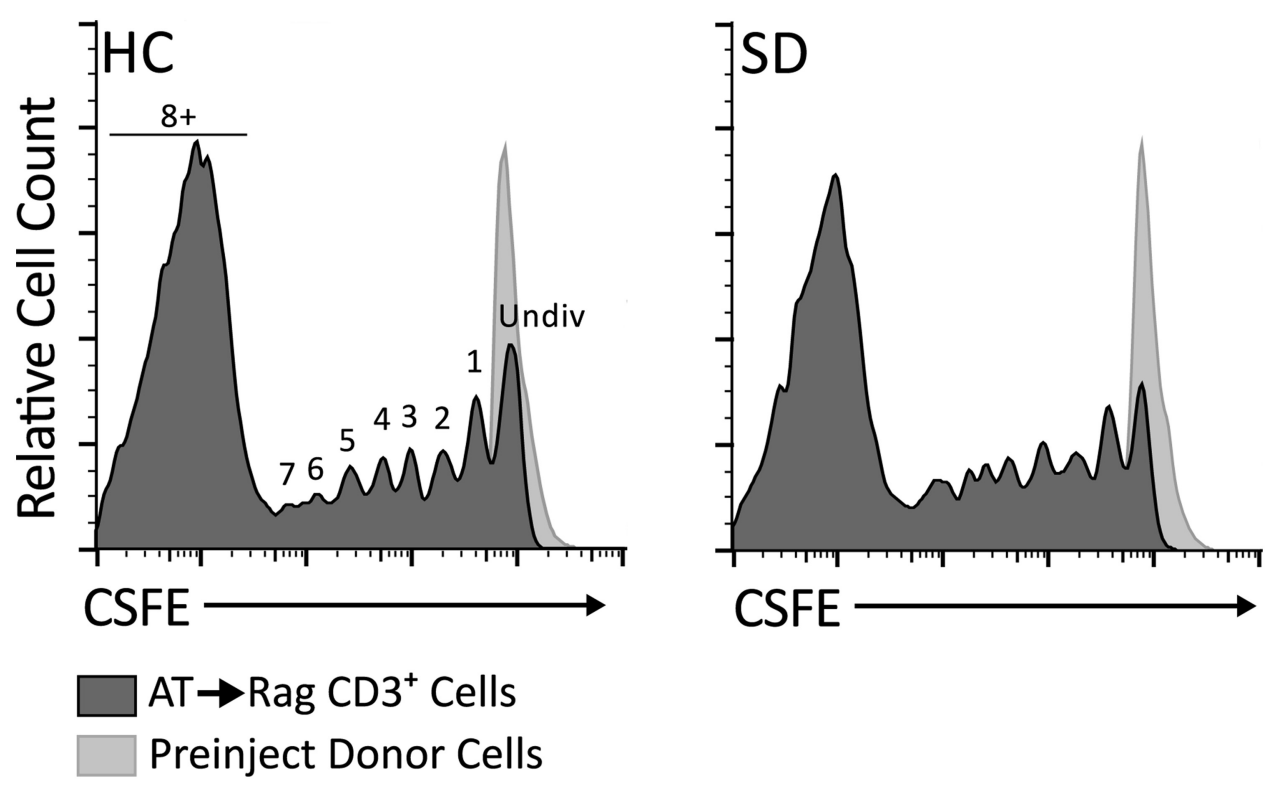

Figure 5. Cell-proliferation rates of adoptively transferred (AT) cells in the Rag $2^{-1-}$ mice were not affected by SD stress in the donor mice. The CFSE intensity histograms show that most cells underwent $>8$ divisions in the period after the two transfers ( 8 and $14 \mathrm{~d}$ prior). Two representative histograms are shown for lymph node cells from HC $\rightarrow$ Rag and SD $\rightarrow$ Rag mice. Successive cell divisions to the left of the undivided peak (obtained from (FSE-labeled donor cells) are labeled $1-7$ and $8+$. Though rates of proliferation trended higher in SD $\rightarrow$ Rag samples, $t$ test of cells in the undivided (Undiv) peak between HC and SD was $p=0.06(n=3-4)$, and no other differences were significant.

findings, Cohen et al. (2006) showed that CNS-autoreactive $\mathrm{T}$ cells were antidepressant, but Treg cells opposed this effect. In contrast, Kim et al. (2012) showed that depleting Treg cells caused an increase in anxiety-like behavior in the elevated-plus maze. Rattazzi et al. (2013), based on data from cross-bred knock-out mouse lines, argued that $\mathrm{CD} 4{ }^{+} \mathrm{T}$ cells correct a naturally existing anxious phenotype in lymphopenic Rag $1^{-1-}$ mice, a phenotype we do not observe for Rag2 ${ }^{-l-}$ mice. We did not use Rag $1^{-l-}$ mice because the Ragl gene is expressed in the brain, notably in the hippocampus (Chun et al., 1991), which may contribute to CNS-related effects seen in this knock-out animal. Interestingly however, in line with our data from $\mathrm{HC}$ derived cells, transfer of $\mathrm{CD}^{+}{ }^{+} \mathrm{T}$ cells from naive mice to Rag $1^{-/-}$mice did not affect anxiety behavior (Rattazzi et al., 2013). Finally, Beurel et al. (2013) showed that Th17-directed $\mathrm{T}$ cells are pro-depressant when transplanted into C57BL/6 mice.

We show here for the first time that otherwise unmanipulated lymphocytes can be modified in vivo by psychological manipulations to exert differential effects on their host. Surprisingly, lymphocytes that experienced the effects of psychological stress were the ones that countered the deleterious effects of the stressor. Remarkably, not only were the behavioral decline and decreased cell proliferation associated with stress reversed in the mice receiving cells from stressed donors, but the pro-inflammatory/ anti-inflammatory blood cytokine profile and brain M1/M2 microglial polarity also were substantially reversed between donor and host. In effect, equilibrium was restored.

In previous work, it has been proposed that stress or depression in people and animals causes lymphocytes to participate in an inflammatory cascade resulting in a disequilibrium precipitating affective and cognitive decline (Miller, 2010). On the other hand, it has been proposed by Schwartz's group that psychological stress might induce an immunological memory within the adaptive immune system that supports stress resilience (Lewitus and Schwartz, 2009). The present study directly tested that hypothesis. The paradigm of adoptive transfer of stress-modified lymphocytes into lymphopenic naive Rag $2^{-1-}$ mice dissociated the contribution of lymphocytes from other contributing factors, and it showed in a straightforward fashion that the adaptive immune system confers stress resilience (antidepressant effects) when and only when it has been primed by stress. Importantly, in departure from the extensive work of Schwartz and Kipnis (2011), the present data do not invoke the requirement of "autoreactive" T cells. Rather, a purely psychological manipulation was sufficient to program leukocytes that had not been manipulated in any other way. Future work will address the basis for the programming and determine which subsets are primarily responsible for the antidepressant effects.

The transferred cells were highly proliferative in the lymphopenic environment of the Rag $2^{-1-}$ host. The present data confirm earlier work showing that lymphocytes divide in lymph nodes and spleen at the rate of approximately once per day after transfer onto a $\mathrm{Rag}^{-1-}$ host (Cho et al., 2000; Dummer et al., 2001). Thus, few undivided cells remained at the time of phenotyping, suggesting that the cellular and humoral influences are stable and passed across cell generations.

A clue to how stress-programmed lymphocytes work to reset homeostasis is provided by the profile of cytokine levels in donor and host blood. As expected, chronic stress elevated inflammatory cytokines in SD donor blood relative to HC control. Strikingly, that profile was reversed in the blood of $\mathrm{SD} \rightarrow$ Rag relative to $\mathrm{HC} \rightarrow$ Rag recipient mice. Blood levels of pro-inflammatory cytokines IL- $1 \beta$ and IL- 17 were lower in the SD $\rightarrow$ Rag mice than in both the $\mathrm{HC} \rightarrow$ Rag mice and naive saline control mice, and levels of the anti-inflammatory cytokine IL- 4 were in the opposite direction-higher in the SD $\rightarrow$ Rag mice than in either of the other groups. In other studies, IL-4 derived from the meninges was shown to maintain performance in a water maze escape task (Derecki et al., 2010). The very low blood levels of IL-4 found in $\mathrm{HC} \rightarrow$ Rag mice are curious, but high levels in the SD $\rightarrow$ Rag animals support the suggestion that IL-4 promotes an antidepressant state. Pro-depressive effects of IL-17, which was reduced in $\mathrm{SD} \rightarrow$ Rag mice, were shown when Th17-programmed cells were introduced into recipient mice (Beurel et al., 2013). The cytokine pro- 
file of the recipient mice, therefore, is consistent with the likely role of key cytokines in mediating the "restorative" effects on behavior and neurogenesis.

Microglia examined ex vivo from stressed donor mice relative to HC mice were more polarized toward the classical M1 inflammatory state, similar to that seen by Frank et al. (2007). The selected M1 genes, IL-1 $\beta$ and IL-6, are associated with inhibited neurogenesis (Ekdahl et al., 2003), which occurs in defeated mice (Schloesser et al., 2010). In striking contrast, the stressprogrammed lymphocytes from stressed donors affected the microglial phenotype in the Rag2 $2^{-1-}$ hosts and skewed their polarity toward the M2 alternative activation profile, which may have beneficial effects on neurogenesis (Battista et al., 2006; Mathieu et al., 2010) and thus may in part underlie increased neurogenesis and improved behavior in the $\mathrm{SD} \rightarrow$ Rag mice.

In summary, these data demonstrate that cells of the adaptive immune system can retain a memory of a cognitive experience, i.e., are not reprogrammed by the host CNS, even after extensive proliferation and turnover, and impart an effect on brain that alters cellular function and behavior. We hypothesize that the immune system is working to maintain homeostasis, mounting a response to a stress challenge in a manner not entirely dissimilar to its response to an immune challenge. Because adoptive transfer in lymphopenic animals is an artificial manipulation required to reveal the protective role of the adaptive immune system, future work in natural models is needed to firmly establish this relationship. Of clinical relevance, the data suggest that differences in the adaptive immune system may account for different susceptibilities (i.e., endogenous stress resilience) across individuals and could potentially be useful in identifying at-risk individuals. Finally, because endogenous changes to peripheral cells are sufficient to induce an antidepressant phenotype, this study establishes the periphery as a viable target for antidepressant therapies that do not need to cross the blood-brain barrier for efficacy.

\section{References}

Battista D, Ferrari CC, Gage FH, Pitossi FJ (2006) Neurogenic niche modulation by activated microglia: transforming growth factor $\beta$ increases neurogenesis in the adult dentate gyrus. Eur J Neurosci 23:83-93. CrossRef Medline

Beurel E, Harrington LE, Jope RS (2013) Inflammatory T helper 17 cells promote depression-like behavior in mice. Biol Psychiatry 73:622-630. CrossRef Medline

Brynskikh A, Warren T, Zhu J, Kipnis J (2008) Adaptive immunity affects learning behavior in mice. Brain Behav Immun 22:861-869. CrossRef Medline

Cherry JD, Olschowka JA, O’Banion MK (2014) Neuroinflammation and M2 microglia: the good, the bad, and the inflamed. J Neuroinflammation 11:98. CrossRef Medline

Cho BK, Rao VP, Ge Q, Eisen HN, Chen J (2000) Homeostasis-stimulated proliferation drives naive $\mathrm{T}$ cells to differentiate directly into memory T cells. J Exp Med 192:549-556. CrossRef Medline

Chun JJ, Schatz DG, Oettinger MA, Jaenisch R, Baltimore D (1991) The recombination activating gene-1 (RAG-1) transcript is present in the murine central nervous system. Cell 64:189-200. CrossRef Medline

Cohen H, Ziv Y, Cardon M, Kaplan Z, Matar MA, Gidron Y, Schwartz M, Kipnis J (2006) Maladaptation to mental stress mitigated by the adaptive immune system via depletion of naturally occurring regulatory $\mathrm{CD} 4{ }^{+} \mathrm{CD} 25{ }^{+}$cells. J Neurobiol 66:552-563. CrossRef Medline

Crawley JN (1985) Exploratory behavior models of anxiety in mice. Neurosci Biobehav Rev 9:37-44. CrossRef Medline

Dantzer R, O'Connor JC, Freund GG, Johnson RW, Kelley KW (2008) From inflammation to sickness and depression: when the immune system subjugates the brain. Nat Rev Neurosci 9:46-56. CrossRef Medline

Derecki NC, Cardani AN, Yang CH, Quinnies KM, Crihfield A, Lynch KR, Kipnis J (2010) Regulation of learning and memory by meningeal immunity: a key role for IL-4. J Exp Med 207:1067-1080. CrossRef Medline
Dummer W, Ernst B, LeRoy E, Lee D, Surh C (2001) Autologous regulation of naive $\mathrm{T}$ cell homeostasis within the $\mathrm{T}$ cell compartment. J Immunol 166:2460-2468. CrossRef Medline

Ekdahl CT, Claasen JH, Bonde S, Kokaia Z, Lindvall O (2003) Inflammation is detrimental for neurogenesis in adult brain. Proc Natl Acad Sci U S A 100:13632-13637. CrossRef Medline

Ernst B, Lee DS, Chang JM, Sprent J, Surh CD (1999) The peptide ligands mediating positive selection in the thymus control $\mathrm{T}$ cell survival and homeostatic proliferation in the periphery. Immunity 11:173-181. CrossRef Medline

Frank MG, Baratta MV, Sprunger DB, Watkins LR, Maier SF (2007) Microglia serve as a neuroimmune substrate for stress-induced potentiation of CNS pro-inflammatory cytokine responses. Brain Behav Immun 21:47-59. CrossRef Medline

Frick LR, Arcos ML, Rapanelli M, Zappia MP, Brocco M, Mongini C, Genaro AM, Cremaschi GA (2009) Chronic restraint stress impairs T-cell immunity and promotes tumor progression in mice. Stress 12:134-143. CrossRef Medline

Gibney SM, Drexhage HA (2013) Evidence for a dysregulated immune system in the etiology of psychiatric disorders. J Neuroimmune Pharmacol 8:900-920. CrossRef Medline

Glaser R, Kiecolt-Glaser JK (2005) Stress-induced immune dysfunction: implications for health. Nat Rev Immunol 5:243-251. CrossRef Medline

Gould E, Tanapat P (1999) Stress and hippocampal neurogenesis. Biol Psychiatry 46:1472-1479. CrossRef Medline

Kigerl KA, Gensel JC, Ankeny DP, Alexander JK, Donnelly DJ, Popovich PG (2009) Identification of two distinct macrophage subsets with divergent effects causing either neurotoxicity or regeneration in the injured mouse spinal cord. J Neurosci 29:13435-13444. CrossRef Medline

Kim SJ, Lee H, Lee G, Oh SJ, Shin MK, Shim I, Bae H (2012) CD4 ${ }^{+}$CD25 ${ }^{+}$ regulatory $\mathrm{T}$ cell depletion modulates anxiety and depression-like behaviors in mice. PLoS One 7:e42054. CrossRef Medline

Lehmann ML, Herkenham M (2011) Environmental enrichment confers stress resiliency to social defeat through an infralimbic cortex-dependent neuroanatomical pathway. J Neurosci 31:6159-6173. CrossRef Medline

Lehmann ML, Brachman RA, Martinowich K, Schloesser RJ, Herkenham M (2013a) Glucocorticoids orchestrate divergent effects on mood through adult neurogenesis. J Neurosci 33:2961-2972. CrossRef Medline

Lehmann ML, Geddes CE, Lee JL, Herkenham M (2013b) Urine scent marking (USM): a novel test for depressive-like behavior and a predictor of stress resiliency in mice. PLoS One 8:e69822. CrossRef Medline

Lehmann ML, Mustafa T, Eiden AM, Herkenham M, Eiden LE (2013c) PACAP-deficient mice show attenuated corticosterone secretion and fail to develop depressive behavior during chronic social defeat stress. Psychoneuroendocrinology 38:702-715. CrossRef Medline

Lewitus GM, Schwartz M (2009) Behavioral immunization: immunity to self-antigens contributes to psychological stress resilience. Mol Psychiatry 14:532-536. CrossRef Medline

Maier SF, Watkins LR (1998) Cytokines for psychologists: implications of bidirectional immune-to-brain communication for understanding behavior, mood, and cognition. Psychol Rev 105:83-107. CrossRef Medline

Mathieu P, Piantanida AP, Pitossi F (2010) Chronic expression of transforming growth factor-beta enhances adult neurogenesis. Neuroimmunomodulation 17:200-201. CrossRef Medline

Miller AH (2010) Depression and immunity: a role for T cells? Brain Behav Immun 24:1-8. CrossRef Medline

Miller AH, Maletic V, Raison CL (2009) Inflammation and its discontents: the role of cytokines in the pathophysiology of major depression. Biol Psychiatry 65:732-741. CrossRef Medline

Min B, Foucras G, Meier-Schellersheim M, Paul WE (2004) Spontaneous proliferation, a response of naive CD4 T cells determined by the diversity of the memory cell repertoire. Proc Natl Acad Sci U S A 101:3874-3879. CrossRef Medline

Murali-Krishna K, Ahmed R (2000) Cutting edge: naive T cells masquerading as memory cells. J Immunol 165:1733-1737. CrossRef Medline

Rattazzi L, Piras G, Ono M, Deacon R, Pariante CM, D’Acquisto F (2013) $\mathrm{CD}^{+}{ }^{+}$but not $\mathrm{CD} 8{ }^{+} \mathrm{T}$ cells revert the impaired emotional behavior of immunocompromised RAG-1-deficient mice. Transl Psychiatry 3:e280. CrossRef Medline 
Schloesser RJ, Lehmann M, Martinowich K, Manji HK, Herkenham M (2010) Environmental enrichment requires adult neurogenesis to facilitate the recovery from psychosocial stress. Mol Psychiatry 15:1152-1163. CrossRef Medline

Schwartz M, Kipnis J (2011) A conceptual revolution in the relationships between the brain and immunity. Brain Behav Immun 25:817-819. CrossRef Medline

Schwartz M, Shechter R (2010) Protective autoimmunity functions by intracranial immunosurveillance to support the mind: the missing link between health and disease. Mol Psychiatry 15:342-354. CrossRef Medline

Segerstrom SC, Miller GE (2004) Psychological stress and the human immune system: a meta-analytic study of 30 years of inquiry. Psychol Bull 130:601-630. CrossRef Medline

Shinkai Y, Rathbun G, Lam KP, Oltz EM, Stewart V, Mendelsohn M, Charron J, Datta M, Young F, Stall AM (1992) RAG-2-deficient mice lack mature lymphocytes owing to inability to initiate $\mathrm{V}(\mathrm{D}) \mathrm{J}$ rearrangement. Cell 68 : 855-867. CrossRef Medline

Silberman DM, Ayelli-Edgar V, Zorrilla-Zubilete M, Zieher LM, Genaro AM (2004) Impaired T-cell dependent humoral response and its relationship with $\mathrm{T}$ lymphocyte sensitivity to stress hormones in a chronic mild stress model of depression. Brain Behav Immun 18:8190. CrossRef Medline

Wolf SA, Steiner B, Wengner A, Lipp M, Kammertoens T, Kempermann G (2009) Adaptive peripheral immune response increases proliferation of neural precursor cells in the adult hippocampus. FASEB J 23:3121-3128. CrossRef Medline

Ziemssen T, Kern S (2007) Psychoneuroimmunology_cross-talk between the immune and nervous systems. J Neurol 254 [Suppl 2]:II8-II11. CrossRef Medline

Ziv Y, Ron N, Butovsky O, Landa G, Sudai E, Greenberg N, Cohen H, Kipnis J, Schwartz M (2006) Immune cells contribute to the maintenance of neurogenesis and spatial learning abilities in adulthood. Nat Neurosci 9:268-275. CrossRef Medline

Zorrilla EP, Luborsky L, McKay JR, Rosenthal R, Houldin A, Tax A, McCorkle R, Seligman DA, Schmidt K (2001) The relationship of depression and stressors to immunological assays: a meta-analytic review. Brain Behav Immun 15:199-226. CrossRef Medline

Zunszain PA, Hepgul N, Pariante CM (2013) Inflammation and depression. Curr Top Behav Neurosci 14:135-151. CrossRef Medline 